\title{
Aerobic heterotrophic microbial activity associated with seagrass roots: effects of plant type and nutrient amendment
}

\author{
Kieryn Kilminster ${ }^{1, *}$, Jay Garland ${ }^{2}$ \\ ${ }^{1}$ Department of Water, Government of Western Australia, PO Box K822, Perth, Western Australia 6842, Australia \\ ${ }^{2}$ Dynamac Corporation, Mail Code DYN-3, Kennedy Space Center, Florida 32899, USA
}

\begin{abstract}
The oxygen dynamics of seagrass roots implicitly influences the associated microbial activity. The oxic zone surrounding roots creates a distinct electrochemical gradient where the concentration of oxygen is highest closest to the root tip and decreases sharply with distance away from the root. Microbes within each micro-niche utilise progressively less energy-favourable electron acceptors (e.g. oxygen, nitrate, sulphate). It is probable that oxygen-consuming bacteria would have greatest activity at or near the root tips of seagrass. This study assessed the potential of a communitylevel physiological profiling assay, based on a high throughput, microtitre-based oxygen sensor, to evaluate aerobic heterotrophs in seagrass ecosystems. Seagrasses were collected from shallow water within the Banana River Estuary, Kennedy Space Center. The sensitivity of the method for characterizing microbial communities associated with seagrasses was tested both spatially (i.e. rhizoplane, rhizosphere) and following imposed light stress (i.e. shading). Results showed that oxygen availability and competition for nutrients defined the microbial response to carbon substrates, with the fastest response and largest peaks for $\mathrm{N}$-containing carbon sources (e.g. asparagine, natural extracts). Aerobic microbial activity was higher for Halodule wrightii than Syringodium filiforme. Primary nitrogen and secondary phosphorus limitation was observed for microbial activity from the rhizoplane and rhizosphere of $H$. wrightii. Shading appeared to reduce nutrient limitation for $H$. wrightii and reduced aerobic microbial activity. The microbial activity and functional response varied between the rhizosphere and rhizoplane, which suggests that microbial activity on this fine spatial scale needs to be considered when evaluating biogeochemistry associated with seagrass sediments.
\end{abstract}

KEY WORDS: Seagrasses · Bacteria · Aerobic heterotrophs · Community-level physiological profiling $\cdot$ Nutrient limitation

\section{INTRODUCTION}

Aerobic microbial activity associated with seagrass sediments is likely to be strongly coupled with the photosynthesis and oxygen dynamics of seagrasses. Seagrasses release oxygen from their roots during periods of photosynthesis (Pedersen et al. 1998, Connell et al. 1999, Jensen et al. 2005), creating a distinct electrochemical gradient where the concentration of oxygen is highest closest to the root tip, decreasing sharply with distance away from the root. During dark periods, oxygen can also passively diffuse from the water col- umn to maintain an oxic rhizosphere (Pedersen et al. 1998, Borum et al. 2006). Microbes within each microniche utilise progressively less energy-favourable electron acceptors (e.g. oxygen, nitrate, sulphate); consequently, aerobic heterotrophs are expected to have the greatest activity at or near the root tips of seagrass. Most studies addressing the microbial activity within sediments associated with seagrass have been carried out on sediment cores and do not necessarily reflect the microbial activity more closely related to seagrass roots. In these studies, microbial activity appears to be strongly coupled with seagrass productivity and is 
commonly enhanced in sediments of seagrass beds in comparison to unvegetated areas (Boon et al. 1986, Pollard \& Kogure 1993, Lee \& Dunton 2000, Holmer et al. 2001). Rates of sulphate reduction, nitrogen fixation and organic matter mineralization are greater in areas of seagrass than in unvegetated areas (Donnelly \& Herbert 1999, Lee \& Dunton 2000, Nielsen et al. 2001). Enhanced microbial activity may partially be a reflection of the heterogenous nature of seagrass sediments, and the fact that factors such as oxygen gradients create micro-niches not available within unvegetated sediments. Heterotrophic activity in the water column appears to be strongly coupled with seagrass dissolved organic carbon (DOC) (Ziegler \& Benner 1999), while estimations suggest that root exudation of DOC from the seagrass Thalassia testudinum may account for 41 to $61 \%$ of the carbon required for sedimentary bacteria (Kaldy et al. 2006). Despite strong coupling shown in some studies, there is contrasting evidence as to whether seagrass is the primary source of carbon for sedimentary bacteria in seagrass meadows (Boschker et al. 2000, Holmer et al. 2001, Jones et al. 2003).

Microbial activity within seagrass sediments is associated not only with the presence but also the activity of seagrasses. The rates of sulphate reduction, nitrogen fixation and other microbial activities associated with seagrass sediment varies diurnally and seasonally (Moriarty \& Pollard 1982, Pollard \& Kogure 1993, Glazebrook et al. 1996, Blaabjerg et al. 1998, Lee \& Dunton 2000). Valisneria americana Michaux, although not strictly a seagrass and commonly regarded as a freshwater plant, tolerates a salinity of half that of seawater at the site investigated by Kurtz et al. (2003). The rhizosphere of this submerged macrophyte harbours distinct microbial communities, when compared to bulk sediment, with a shift in the types of bacteria present when the plant is light limited (Kurtz et al. 2003). Light limitation of the plant would decrease photosynthetically released oxygen (Pedersen et al. 1998, Connell et al. 1999, Jensen et al. 2005), thus potentially changing the thickness of the oxic layer surrounding the roots. Different bacterial communities were also found associated with the roots and the bulk sediment of the seagrass Zostera marina, with sulphate-reducers more prevalent in the bulk sediment (Jensen et al. 2007). These studies support the link between bacterial activity and aquatic plant productivity.

The aim of the present study was to evaluate the potential use of a community-level physiological profiling (CLPP) assay using oxygen (BD-oxy) to evaluate aerobic heterotrophs in seagrass ecosystems. BD-oxy CLPP is a sole-substrate utilization test using an oxygen-sensitive fluorophore, which is quenched in the presence of oxygen, to approximate microbial respira- tion. The method was first described by Garland et al. (2003). There were many problems associated with earlier CLPP methods (Konopka et al. 1998), and BDoxy CLPP overcomes many of these issues by allowing for the use of lower substrate concentrations (i.e. less potential for selective enrichment) and the easy manipulation of assay conditions (e.g. nutrient amendments) (Väisänen et al. 2005).

A multi-staged approach was adopted to assess the sensitivity of the method for characterizing microbial communities associated with seagrass species, both spatially (i.e. rhizoplane, rhizosphere) and following imposed light stress (i.e. shading). It was hypothesized that (1) seagrasses would harbour aerobic heterotrophic microbial communities with distinctive levels of activity in the rhizoplane and rhizosphere due to the oxygen gradient, (2) the microbes associated with a species of seagrass would be acclimatized to the watersoluble plant extract from the same seagrass (in preference to an extract derived from a different seagrass), and (3) the oxygen-consuming microbes associated with seagrass-vegetated sediment would be sensitive to changes in oxygen release from the plant following shading (i.e. variation in photosynthetically produced and released oxygen).

\section{MATERIALS AND METHODS}

Study site and field sampling methods. Seagrasses were collected from the Banana River, Indian River Lagoon Estuary, Florida, within the Kennedy Space Center from May to July 2007. Samples of Halodule wrightii Aschers. and Syringodium filiforme Kütz were collected from shallow ( $1 \mathrm{~m}$ deep) seagrass meadows at 3 sites. The light requirements of Halodule wrightii and Syringodium filiforme are reported to be $17.2 \%$ of surface irradiance in the Indian River Lagoon (Duarte 1991, Dennison et al. 1993), and the 2 species are often found at similar depths within the lagoon. Locations of the sampling sites were: Site A, $28^{\circ} 30^{\prime} 23^{\prime \prime} \mathrm{N}$, $80^{\circ} 35^{\prime} 59^{\prime \prime} \mathrm{W}$; Site B, $28^{\circ} 31^{\prime} 47^{\prime \prime} \mathrm{N}, 80^{\circ} 36^{\prime} 35^{\prime \prime} \mathrm{W}$; and Site C, $28^{\circ} 30^{\prime} 41^{\prime \prime} \mathrm{N}, 80^{\circ} 35^{\prime} 46^{\prime \prime} \mathrm{W}$ (Fig. 1). Intermingled monospecific patches of $H$. wrightii and $S$. filiforme were present within the meadows at these sites, which allowed collection of cores of each individual seagrass species. Sediment associated with seagrass appeared similar at all sites, with fine grey sands dominant at all sites. Diurnal differences in substrate utilisation were avoided by sampling seagrass at a similar time each morning.

In situ shading of Halodule wrightii was set up near Site A. Sections $\left(1 \mathrm{~m}^{2}\right)$ of shadecloth (flyscreen) were secured horizontally approximately $30 \mathrm{~cm}$ above the seagrass canopy by attaching them to 4 perspex pick- 


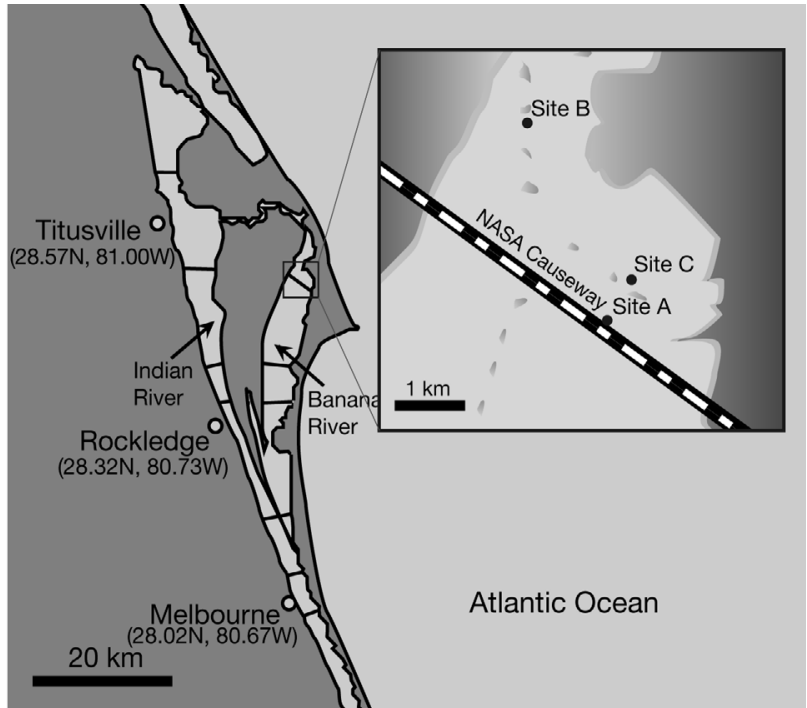

Fig. 1. East coast of Florida, USA, with inset showing sampling locations within the Banana River Estuary, Kennedy Space Center

ets which were pushed into the sediment. Six replicate shading treatments were constructed parallel to the shoreline approximately $6 \mathrm{~m}$ apart. Rhizomes were severed $3 \mathrm{~d}$ after the in situ shading was erected by cutting approximately $10 \mathrm{~cm}$ deep into the sediment around the circumference of each $1 \mathrm{~m}^{2}$ treatment. Rhizomes of controls ( $1 \mathrm{~m}^{2}$ of unshaded seagrass marked with flagging tape) were also severed at this time. Photosynthetically active radiation (PAR) was measured with an underwater LI-COR light meter. In the shaded treatments PAR was reduced by $55 \%$ at the start of the experiment and shading was likely to increase substantially during the 3 wk deployment (due to algal overgrowth on the shadecloth). There was minor algal epiphytic growth on seagrasses, similar between shaded and unshaded seagrasses; this was not expected to significantly influence the interception of light by seagrsses. The final shading level was not determined due to equipment failure. A $5 \%$ natural attenuation of surface PAR irradiance was observed at the canopy depth for unshaded seagrass at the start of the experiment.

Cores of seagrass were collected with PVC tubing ( $7.6 \mathrm{~cm} \varnothing$ ) pushed into the sediment to a depth of at least $15 \mathrm{~cm}$ and retrieved with suction. Overlying water was gently drained from the coring apparatus before collecting the seagrass sediment plug. Plugs of sediment were placed in plastic bags and transported back to the laboratory, typically within $1 \mathrm{~h}$ of collection. The sediment was kept at room temperature and processed within $2 \mathrm{~h}$.

Laboratory processing of samples. Plants were gently shaken to remove unattached sediment from the roots, which ranged in length from 3 to $10 \mathrm{~cm}$. Roots from 10 nodes within each core were excised and placed in a sterile beaker. Standardised root masses ( 0.05 g dry weight [DW] per sample; mean \pm $\mathrm{SD}=0.044 \pm 0.01 \mathrm{~g} \mathrm{DW})$ provided a means to compare inoculum responses without determining cell density. Twenty $\mathrm{ml}$ of sterile saline solution (20 ppt $\mathrm{NaCl}$ in deionised water [DI], filter-sterilised) was added to the beakers containing the root samples. Roots were gently rinsed free of most attached sediment and placed into a $50 \mathrm{ml}$ centrifuge tube also containing $20 \mathrm{ml}$ of sterile saline solution and $5 \mathrm{ml}$ of glass beads. The sediment-saline solution in the beaker was agitated by swirling for $3 \mathrm{~min}$ and the resultant solution became the inoculum for what we term the 'rhizosphere'. The sediment-free roots within the centrifuge tube were shaken with the glass beads for $3 \mathrm{~min}$ and the resultant solution became the inoculum for what we term the 'rhizoplane'. Inoculum $(160 \mu \mathrm{l})$ and carbon substrate $(80 \mu \mathrm{l})$ were added to give a total volume of $240 \mu \mathrm{l}$ in each well of the BDoxy microtitre plate (Table 1 ). Where nutrient solution was also added to microtitre wells, a more concentrated inoculum (made from $15 \mathrm{ml}$ of sterile saline solution rather than $20 \mathrm{ml}$ ) was needed to keep final concentration constant across treatments. In the nutrient supplemented experiments, each well was made up of $120 \mu \mathrm{l}$ of the concentrated inoculum, $80 \mu \mathrm{l}$ of carbon substrate and $40 \mu \mathrm{l}$ of either nutrient solution or DI (Table 1). The BD-oxy microtitre plate contained an oxygen-sensitive fluorophore within a gel layer on the bottom of each well. The fluorophore is quenched in the presence of oxygen, resulting in fluorescence development with microbial respiration. The top of the well was sealed with an oxygen-impermeable film (Titer-Tops, Diversified Biotechs) to limit additional oxygen inputs and/or cross-contamination. The plate was then incubated at $30^{\circ} \mathrm{C}$ and fluorescence measurements taken every $15 \mathrm{~min}$ for $48 \mathrm{~h}$ in a Dynex MFX Microplate fluorometer in bottom-reading mode (485 nm excitation and $604 \mathrm{~nm}$ emission wavelengths).

Nutrient addition. Nitrogen and phosphorus were added to wells to examine potential nutrient limitations on microbial activity within the microtitre wells. In the nutrient supplemented experiments, nitrogen $\left(\left[\mathrm{NH}_{4}\right]_{2} \mathrm{SO}_{4}\right)$ and phosphorus $\left(\mathrm{KH}_{2} \mathrm{PO}_{4}\right)$ were added to the wells at a ratio approximately equal to the Redfield ratio, providing a final concentration in the wells of $10 \mathrm{ppm}$ nitrogen and $1.4 \mathrm{ppm}$ phosphorus.

Preparation of carbon substrates. The carbon sources provided as substrates for the microbial community were either seagrass-derived natural extracts or sole carbon substrates. The optimal concentration of the natural extract for microbial response was deter- 
mined with a preliminary experiment (a dilution series; data not shown). Natural extracts were prepared by either freeze-drying or oven-drying roots and rhizomes before extracting $\sim 0.5 \mathrm{~g}$ of ground sample in $50 \mathrm{ml}$ of DI for $1 \mathrm{~h}$ at $\sim 80^{\circ} \mathrm{C}$. Volume was accurately made up to $150 \mathrm{ml}$ and filter-sterilised. Preliminary experiments showed no significant differences between freeze-dried or oven-dried natural extracts, so oven-dried extracts were used in the experiments reported in detail here. Stock solutions of sole carbon substrates were prepared at $300 \mathrm{ppm}$ concentration and filter-sterilised. The final concentration in the microtitre wells was $100 \mathrm{ppm}$ for sole substrates. Preliminary experiments were carried out on a large range of sole substrates (potato starch, D-[+]-mannose, carboxy-methyl cellulose, acetate, L-argine, Lasparagine, L-phenylalanine, p-coumaric acid, D-[+]galacturonic acid, ethanol, toluene and propionic acid), although due to well number capacity a reduced set of sole substrates was chosen for the experiments reported in detail. DI, mannose, L-asparagine and acetate were constant across all experiments, with propionic acid introduced where space in well layout allowed (Table 1). Killed controls were carried out in preliminary experiments with the addition of formalin to the wells prior to incubation, as there is the potential of a chemical reaction with oxygen in very reduced sediments. The killed controls demonstrated that nonbiological consumption of oxygen did not contribute significantly to the results.

Data analysis. We studied the kinetics of the fluorescent signals in the microtitre plates from which we derived 3 different variables allowing us to make meaningful comparisons between wells. The fluorescent signal in each well measured after $1 \mathrm{~h}$ of incubation was used as the standard to calculate normalised fluorescence units (NFU) to enable comparisons among wells, i.e. fluorescent signal at time $t$ divided by the fluorescent signal at time $t=1 \mathrm{~h}$. From the individual curves obtained, 3 variables were retrieved for each well, comprising the minimum response time (MinR), the maximum response time $\left(T_{\max }\right)$ and the maximum peak (Peak). MinR was the time taken to reach a $10 \%$ increase in fluorescence with respect to the normalised fluorescence signal at $1 \mathrm{~h}, T_{\max }$ was the time taken to reach the maximum fluorescence observed defined from the start of the incubation time and Peak was the maximum normalised fluorescence observed. MinR is an estimate of the lag in microbial response and is likely a reflection of the degree to which the community is poised to utilise a particular substrate. Peak correlates to the lowest dissolved oxygen level in the gel layer. This drop in dissolved oxygen should reflect the overall rate of oxygen consumption, since the greater the respiration rate, the faster the rate of depletion in oxygen. However, it is important to note that we are not measuring total oxygen use in the well, but rather the oxygen dynamics within the gel layer at the bottom of the well.

Data were log-transformed if necessary and standardised prior to multivariate analysis using principal components analysis (PCA). ANOVA and post hoc tests were used to determine significant differences between means in univariate data.

\section{RESULTS}

\section{Region: rhizosphere vs. rhizoplane}

Significant differences were observed for microbial responses associated with the inoculum from Halodule wrightii rhizosphere and rhizoplane communities. This separation was distinctive in all experiments and was

Table 1. Overview of experiments

\begin{tabular}{|c|c|c|c|c|c|c|c|}
\hline Experiment & Site & Date & Species & Region & $\begin{array}{c}\text { Natural extract } \\
\text { substrate }\end{array}$ & Sole substrate & $\begin{array}{c}\mathrm{N}+\mathrm{P} \text { addition } \\
(+/-)\end{array}$ \\
\hline Region & $\mathrm{A}, \mathrm{B}, \mathrm{C}$ & $\begin{array}{l}\text { 3-9 July } \\
\text { 18-25 July }\end{array}$ & Halodule wrightii & $\begin{array}{l}\text { Rhizosphere } \\
\text { Rhizoplane }\end{array}$ & & $\begin{array}{c}\text { Deionised water } \\
\text { Mannose } \\
\text { Asparagine } \\
\text { Acetate }\end{array}$ & - \\
\hline 2 species & $\mathrm{A}, \mathrm{B}, \mathrm{C}$ & $\begin{array}{l}3 \text { July } \\
10 \text { July } \\
18 \text { July }\end{array}$ & $\begin{array}{c}\text { H. wrightii } \\
\text { Syringodium filiforme }\end{array}$ & $\begin{array}{l}\text { Rhizosphere } \\
\text { Rhizoplane }\end{array}$ & $\begin{array}{l}\text { Halodule rhizomes } \\
\text { Halodule roots } \\
\text { Syringodium rhizomes } \\
\text { Syringodium roots }\end{array}$ & $\begin{array}{c}\text { Deionised water } \\
\text { Mannose } \\
\text { Asparagine } \\
\text { Acetate }\end{array}$ & - \\
\hline Shading & A & $\begin{array}{l}20 \text { July } \\
23 \text { July } \\
25 \text { July }\end{array}$ & H. wrightii & $\begin{array}{l}\text { Rhizosphere } \\
\text { Rhizoplane }\end{array}$ & Halodule rhizomes & $\begin{array}{c}\text { Deionised water } \\
\text { Mannose } \\
\text { Asparagine } \\
\text { Acetate } \\
\text { Propionic acid }\end{array}$ & + \\
\hline
\end{tabular}


consistent over time. Results were pooled for 6 sampling occasions over 2 time periods: 3 to 10 July and 18 to 25 July. Nine samples in each time period were examined for substrate utilisation of mannose, asparagine, acetate and DI for both rhizosphere and rhizoplane regions. The results from these 2 separate weeks of sampling (including samples from all sites) resulted in very similar principal components with over $70 \%$ of variation captured in each case for the first 2 principal components. PC1 accounted for 57 and $62 \%$ of the variation across the 2 sampling weeks, respectively. For both weeks of sampling, PCI was dominated by negative coefficients for Peak (mannose, acetate and DI) and positive coefficients for MinR (DI, mannose, asparagine and acetate) and $T_{\max }$ (asparagine). The consistent separation of $H$. wrightii rhizoplane and rhizosphere over time is demonstrated by the samples for the $2 \mathrm{wk}$ of sampling plotted against principal components calculated for the data collected in Week 1 (Fig. 2). The separation between rhizosphere and rhizoplane samples is dominated by differences in PC1.

Functional differences in substrate utilisation were also observed as there was an interaction between region (rhizosphere and rhizoplane) and the substrate responses (MinR and Peak). The rhizosphere did not show a consistent increase or decrease in substrate response across all substrates when compared to the rhizoplane (Fig. 3). This suggests that the microbial populations associated with each region are likely to have a different functional profile, as the substrate response differs.

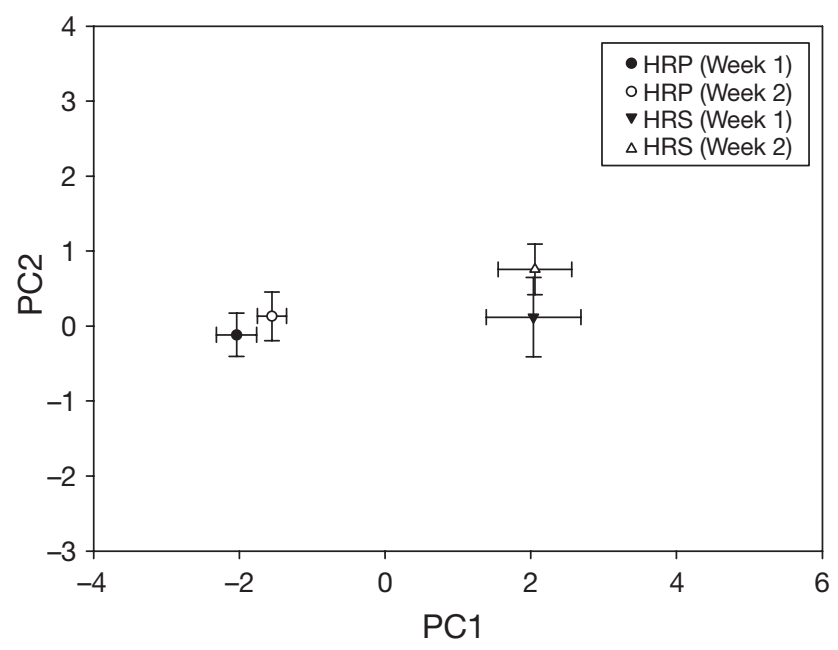

Fig. 2. Significant separation was observed along the PC1 axis for Halodule wrightii rhizoplane (HRP) and rhizosphere (HRS) samples for $2 \mathrm{wk}$ of sampling for respiration response to the substrates deionised water, mannose, asparagine and acetate. Data (mean $\pm \mathrm{SE}, \mathrm{n}=9$ ) are plotted against principal components calculated for the first week of samples for all parameters and illustrate that HRP and HRS show consistent differences over time along the $\mathrm{PC} 1$ axis
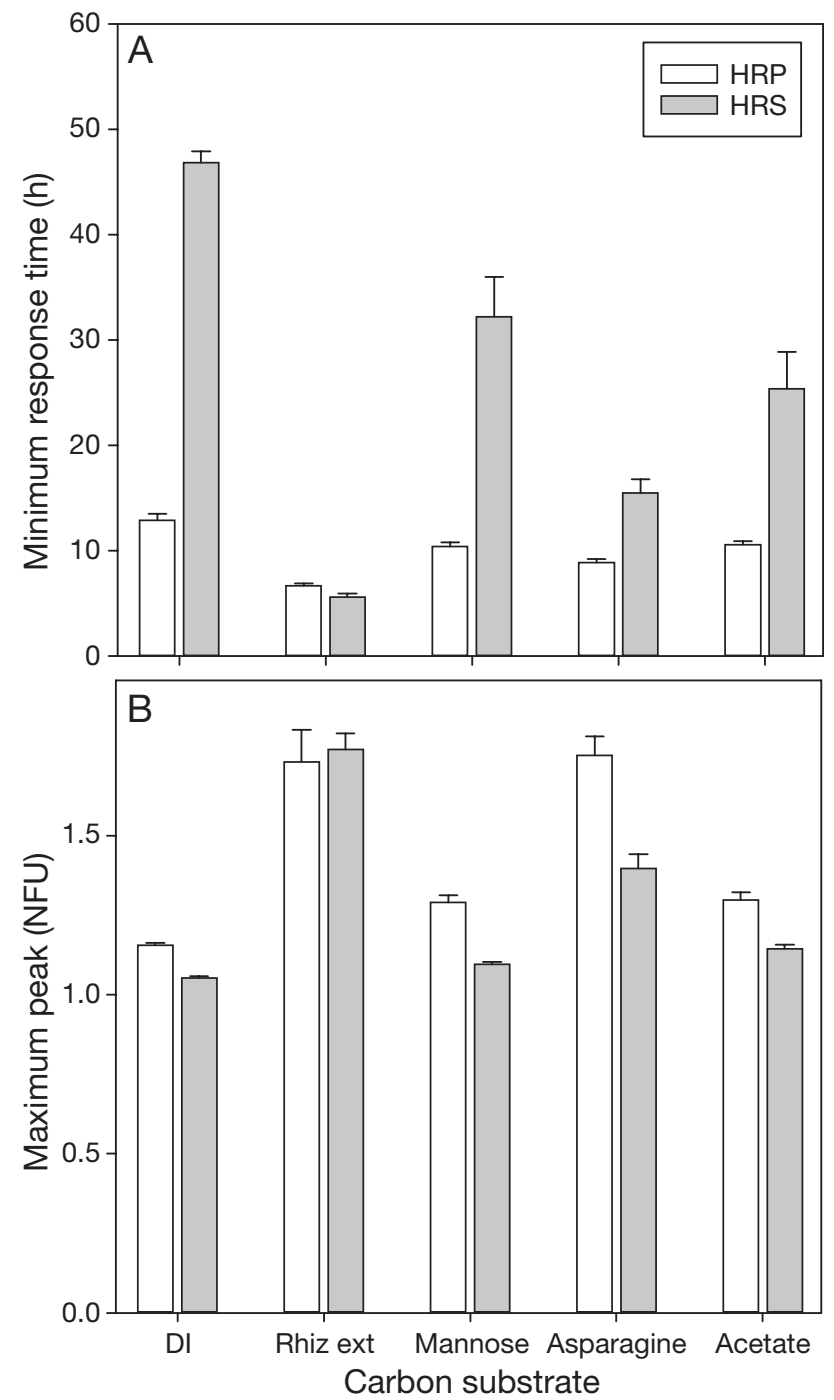

Fig. 3. (A) Average minimum response times and (B) average maximum peak for Halodule wrightii rhizoplane (HRP) and rhizosphere (HRS) samples. Responses to the substrates deionised water (DI), H. wrightii rhizhome extract (Rhiz ext) mannose, asparagine and acetate are combined for both weeks of sampling (mean $+\mathrm{SE}, \mathrm{n}=18$ ). NFU: normalised fluorescent unit

\section{Species comparison: Halodule vs. Syringodium}

Samples of both Halodule wrighti and Syringodium filiforme from 3 locations (Sites A, B and C) were compared for differences related to species and region. The responses to sole substrates (mannose, asparagine and acetate plus DI control) and natural extracts from each of the seagrasses were examined.

Rhizosphere microbial communities from Halodule wrightii and Syringodium filiforme responded similarly to the sole substrates, whilst rhizoplane microbial communities from the 2 seagrass species showed minor differences (Fig. 4A). The plot of PC1 versus PC2 accounts 


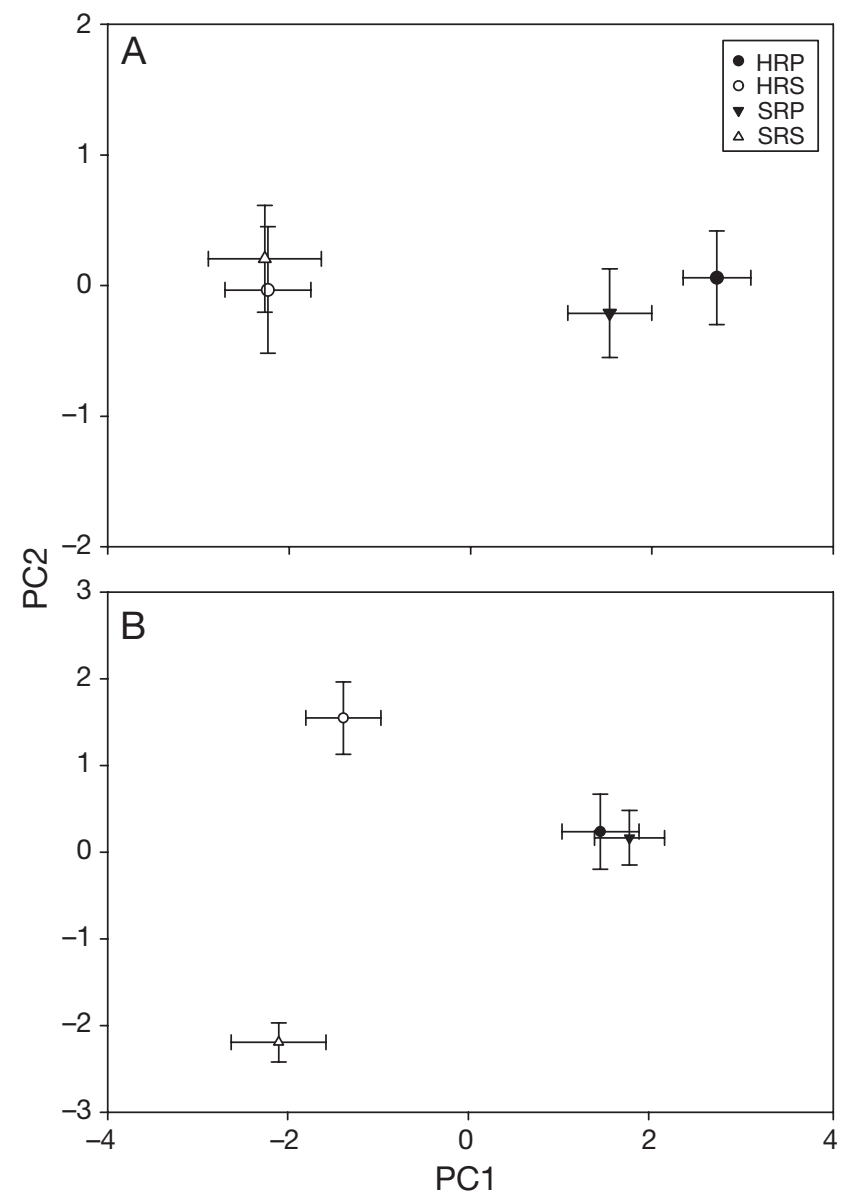

Fig. 4. Principal components analysis of the response of Halodule wrightii rhizoplane (HRP), $H$. wrightii rhizosphere (HRS), Syringodium filiforme rhizoplane (SRP) and S. filiforme rhizosphere (SRS) samples to (A) the sole carbon substrates deionised water (DI), mannose, asparagine and acetate (mean $\pm \mathrm{SE}, \mathrm{n}=9$ ) and (B) natural extracts (extracts were derived from dried below-ground material of the 2 seagrasses)

for $69 \%$ of the variation in all parameters (MinR, $T_{\max }$ and Peak) for the substrates DI, mannose, asparagine and acetate. The differences between rhizosphere and rhizoplane samples dominate the response with higher Peaks and faster MinRs for the rhizoplane than rhizosphere samples for both species. The minor differences between rhizoplane samples were due to faster MinRs and larger Peaks for $H$. wrightii than $S$. filiforme (in response to sole substrates).

The microbial response to natural extracts showed significant differences between species for the rhizosphere but not the rhizoplane samples (Fig. 4B). The plot of PC1 versus PC2 accounts for $61.1 \%$ of the variation in all parameters for the natural extracts from the root and rhizomes of both seagrasses. The difference in response between the rhizosphere samples was due to larger Peaks and faster time to reach maximum and minimum responses for the Halodule wrightii rhizosphere sample when compared to the Syringodium filiforme rhizosphere sample. There did not appear to be preferencial utilisation of $H$. wrightii extracts by $H$. wrightii-associated microbial communities, nor preferential utilisation of $S$. filiforme extracts by $S$. filiformeassociated microbial communities. Rather, MinRs for all natural extracts were faster for $H$. wrightii than $S$. filiforme rhizoplane and rhizosphere samples.

The most significant difference across all substrates (natural extracts and sole carbon substrates) was observed in the MinRs. Rhizoplane samples reached a $10 \%$ increase in normalised fluorescence significantly faster than rhizosphere samples for both species of seagrass. MinRs were also faster for Halodule wrightii than for Syringodium filiforme (Fig. 5).

\section{Shading experiment}

Samples from the in situ shading of Halodule wrightii were analysed for differences due to region, shading and nutrient supplementation during incubation. PCA was used to explore data for all samples, substrates (DI, rhizome extract, mannose, asparagine, acetate and propionic acid) and response variables. Most variation was due to nutrient supplementation, with significant variation again due to region (Fig. 6). The plot of PC1 versus PC2 accounts for $70 \%$ of the variation observed for the data set. Supplementation of microtitre wells with nitrogen and phosphorus resulted in tight clustering of samples and a shift along the PC1 axis. The differences with region were associated with the PC2 axis. Shading

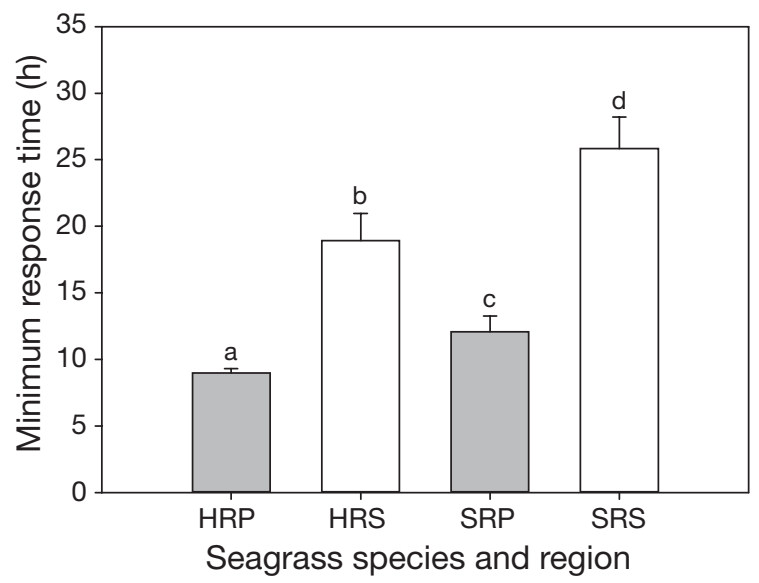

Fig. 5. Minimum response times (mean $+\mathrm{SE}, \mathrm{n}=64-72$ ) for all substrates (natural and sole) for Halodule wrightii rhizoplane (HRP), H. wrightii rhizosphere (HRS), Syringodium filiforme rhizoplane (SRP) and $S$. filiforme rhizosphere (SRS). Minimum response times were significantly faster for rhizoplane than rhizosphere samples, and for $H$. wrightii than $S$. filiforme. Bars with different letters are significantly different $(p<0.05)$ 


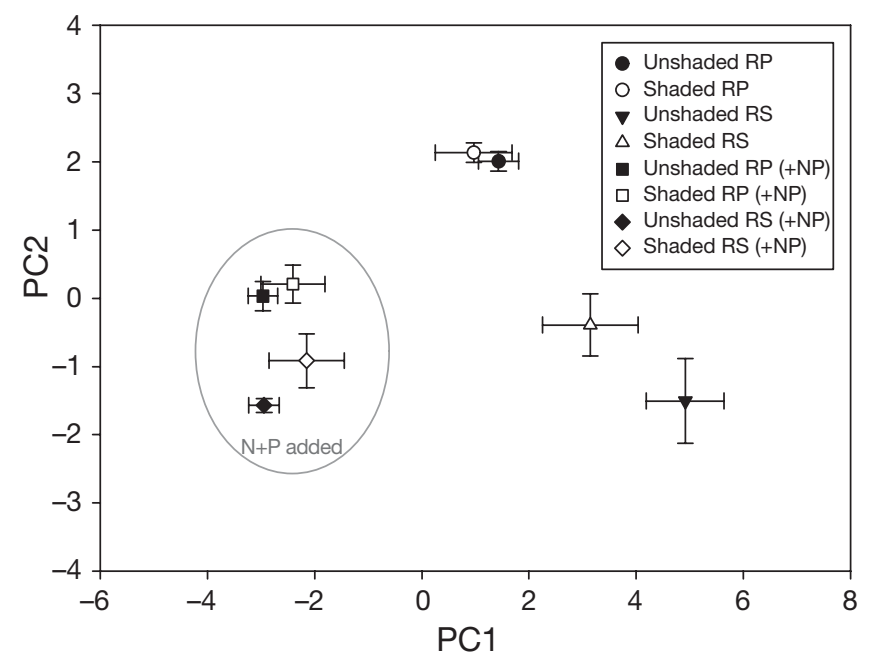

Fig. 6. Principal components analysis of the response of Halodule wrightii rhizosphere (RS) and rhizoplane (RP) samples, with and without shading treatment to all substrates: deioinised water, $H$. wrightii rhizome extract, mannose, asparagine, acetate and propionic acid (mean $\pm \mathrm{SE}, \mathrm{n}=6$ ). Grey circle highlights samples where nitrogen and phosphorus were added to the microtitre wells prior to incubation. Although differences due to shading were observed, the differences due to nutrient addition and region (rhizosphere/ rhizoplane) dominated responses
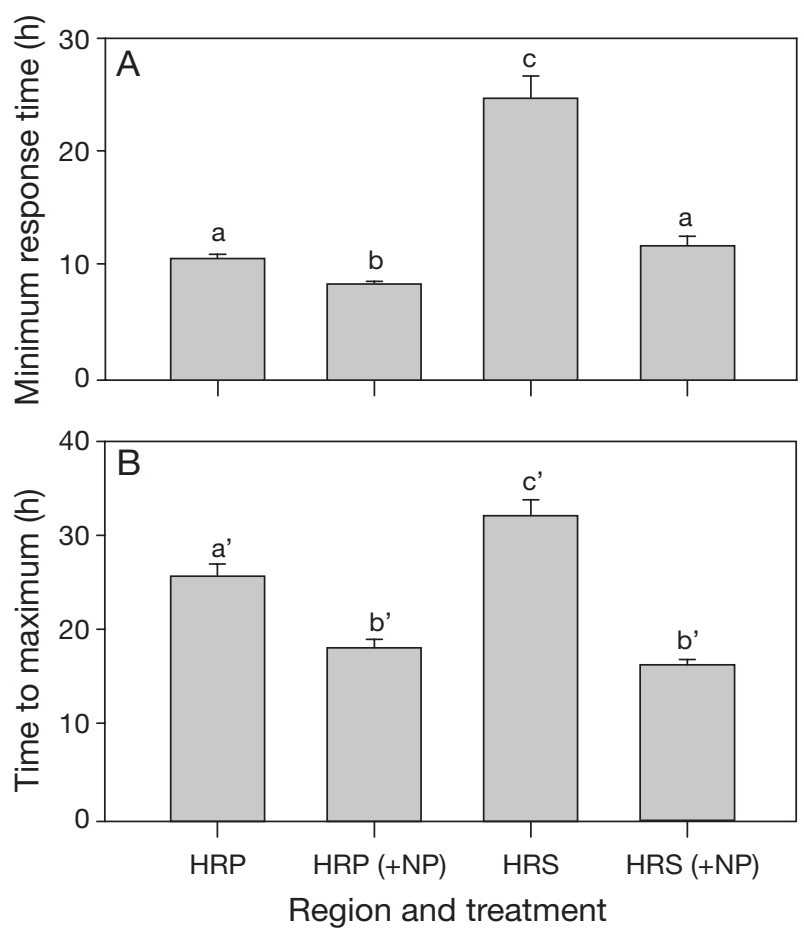

Fig. 7. (A) Average minimum response times and (B) average time to maximum peak for Halodule wrightii rhizoplane (HRP) and rhizosphere (HRS) samples with (+NP) and without nutrient addition to BD-oxy microtitre plates prior to incubation. Response times are for shaded and unshaded treatments combined for all carbon substrates (mean $+\mathrm{SE}, \mathrm{n}=72$ ). Bars with different letters are significantly different $(p<0.05)$

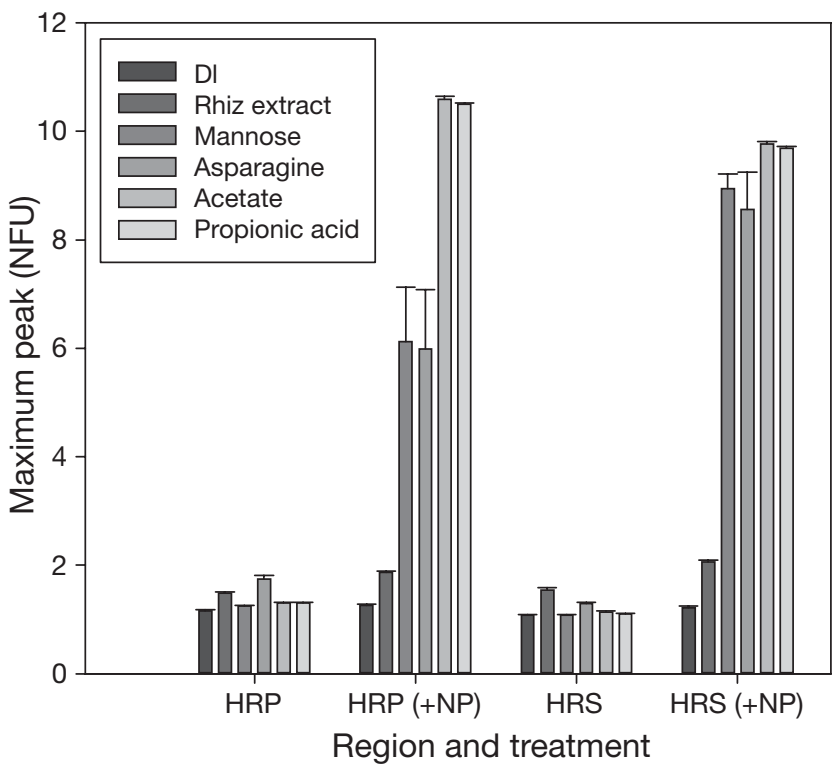

Fig. 8. Maximum peak response (mean $+\mathrm{SE}, \mathrm{n}=6$ ) for unshaded Halodule wrightii rhizoplane (HRP) and rhizosphere (HRS) samples, with (+NP) and without nutrients to all substrates: deioinised water (DI), $H$. wrightii rhizome extract (Rhiz extract), mannose, asparagine, acetate and propionic acid. NFU: normalised fluorescence units. Nutrient addition significantly increased maximum peak response when nutrients were added to the wells prior to incubation

had a smaller effect, with some separation from the respective unshaded counterpart demonstrated in the PCA. The effect of shading appeared stronger for the rhizosphere samples than the rhizoplane samples.

Nutrient addition significantly reduced both time to MinR (Fig. 7A) and $T_{\max }$ (Fig. 7B) for both rhizosphere and rhizoplane samples. The average response to substrates was faster for rhizoplane samples, regardless of whether nutrients were added. Peaks increased for all substrates following nutrient addition for both rhizoplane and rhizosphere samples (Fig. 8). The increase in Peak was greatest for mannose, asparagine, acetate and propionic acid. In contrast, the increase in Peak for DI and rhizome extract substrates was slight following the addition of nutrients. Again there was a lack of consistency in the relative response to each substrate by the rhizosphere and rhizoplane inoculums (with or without nutrient addition), suggesting differences in functional profile between the regions.

For all substrates individually, without nutrient addition to the wells, rhizoplane samples had faster MinR than rhizosphere samples (Fig. 9), with the possible exception of the natural extract (Halodule wrightii rhizome extract), whose response time was much reduced in the rhizosphere relative to the sole substrates (Fig. 9B).

Shading appeared to mostly influence the rhizosphere samples, where, despite significant variation, the response times were reduced across all sub- 


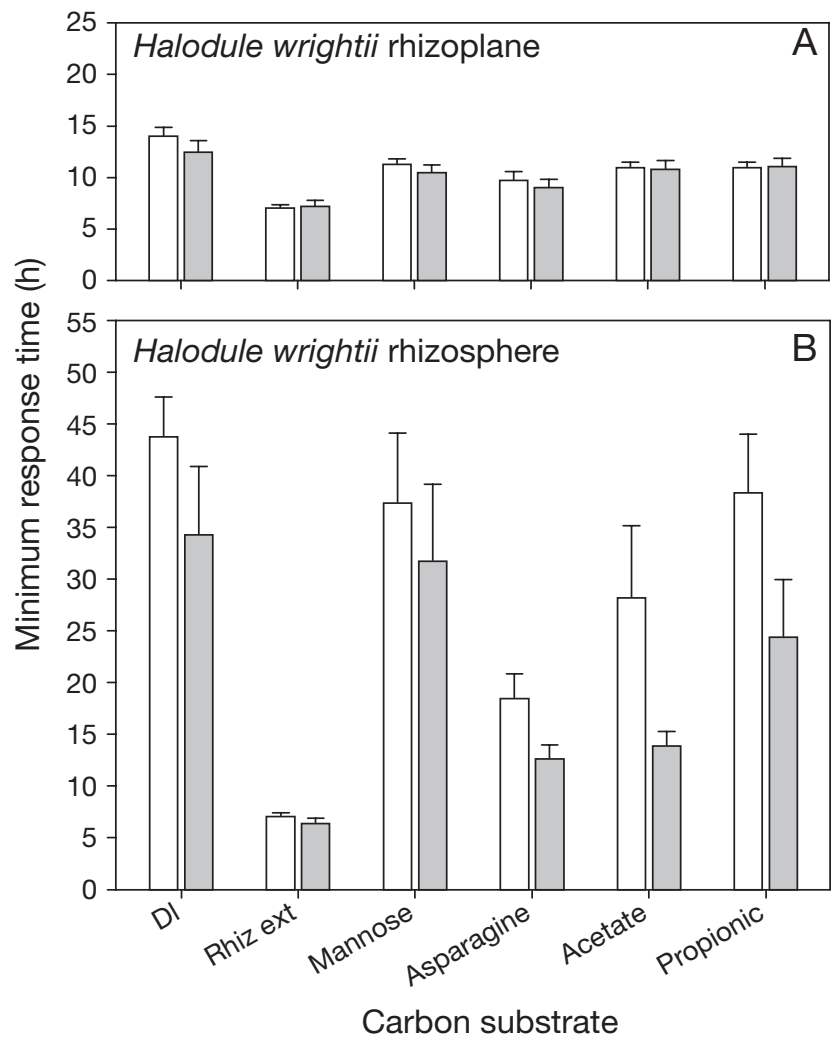

Fig. 9. Minimum response times for Halodule wrightii (A) rhizoplane and (B) rhizospere samples without nutrient supplementation to all substrates: deioinised water (DI), $H$. wrightii rhizome extract (Rhiz ext), mannose, asparagine, acetate and propionic acid (Propionic). Average (mean $\pm \mathrm{SE}, \mathrm{n}=$ 6) minimum response time is smaller for rhizoplane than rhizosphere samples in shaded (grey bars) than unshaded treatments (white bars). Shading has a greater effect on this parameter for rhizosphere than rhizoplane samples

strates tested (Fig. 9B). Shading also increased Peak for both rhizoplane and rhizosphere samples across all substrates tested (Fig. 10). Substrates containing nitrogen (asparagine and Halodule wrightii rhizome extract) resulted in the highest Peaks for both rhizosphere and rhizoplane samples. Peaks were higher for rhizoplane than rhizosphere samples for most substrates tested (Fig. 10).

\section{DISCUSSION}

Most research concerning microbial communities associated with seagrass sediment has focused on single measures of microbial function within sediment cores (e.g. sulphate reduction or nitrogen fixation rates) (Welsh et al. 1996, Blaabjerg \& Finster 1998, Blaabjerg et al. 1998, Hansen et al. 2000). Many of these studies have illustrated the importance of plant-

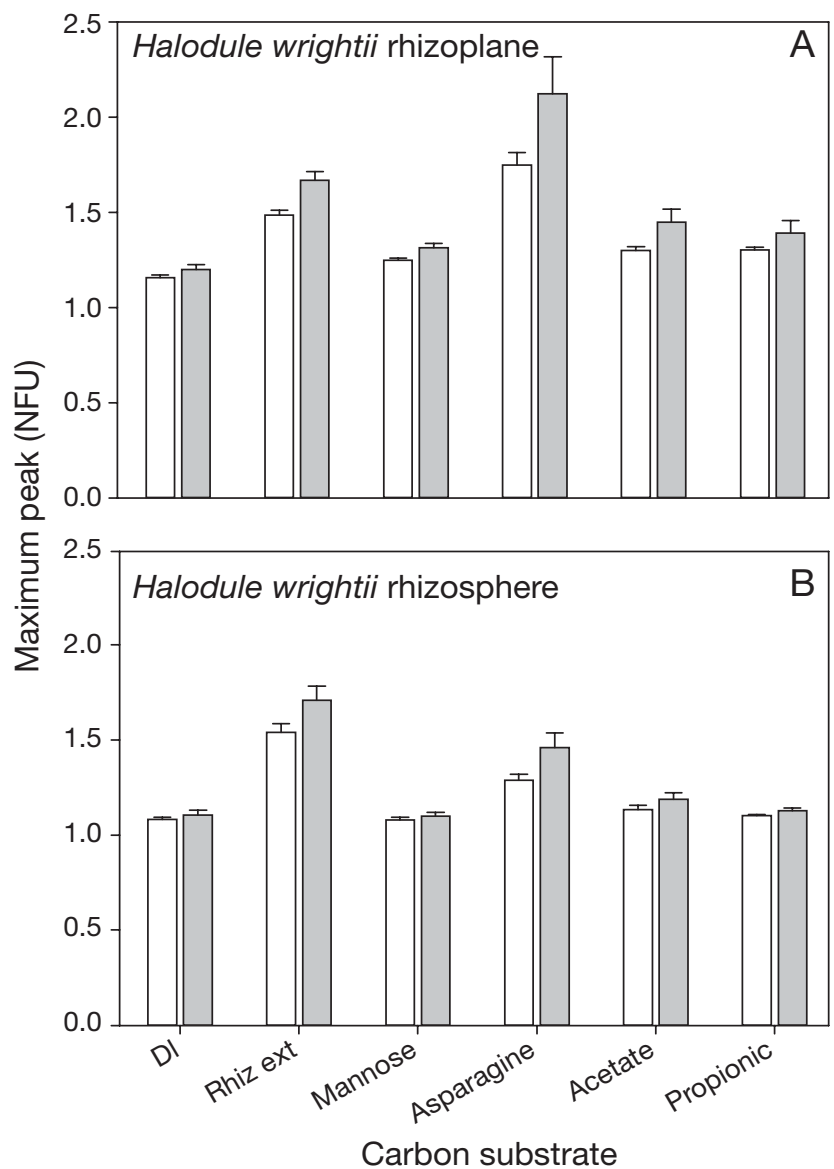

Fig. 10. Maximum peak response for Halodule wrightii (A) rhizoplane and (B) rhizosphere samples without nutrient supplementation to all substrates: deioinised water (DI), Halodule rhizome extract (Rhiz ext), mannose, asparagine, acetate and propionic acid (Propionic). NFU: normalised fkuorescence unit. Average (mean $\pm S E, n=6$ ) maximum fluorescence peak is greater in shaded (grey bars) than unshaded treatments (white bars)

derived organic matter in fuelling microbial activity (Welsh et al. 1997, Blaabjerg et al. 1998, Holmer et al. 2004, Smith et al. 2004), with higher rates of sulphate reduction within seagrass sediments than in unvegetated sediments (Hansen et al. 2000, Holmer et al. 2001). Despite these advances in understanding single microbial processes, only a few studies have investigated the microbial community diversity of these systems. For example, prokaryotic diversity in Zostera noltii-colonized sediments was evaluated with $16 \mathrm{~S}$ rDNA methods (Cifuentes et al. 2000) and cultivation techniques were used to compare microbial processes within sediment of Halodule wrightii, Valisneria americana (Küsel et al. 2006) and Zostera noltii (Cifuentes et al. 2003). Recently, molecular work by Jensen et al. (2007) showed clear differences in the microbial community associated with $Z$. marina roots and the sur- 
rounding sediment. The present study contributes to our understanding of the microbial community associated with seagrasses. The microbial community was evaluated from a multi-functional perspective with BD-oxy CLPP. Repeatable, consistent patterns in substrate utilization suggest that considerable variation in the function of the whole aerobic microbial community exists within seagrass beds. Specifically, we found microbial responses varied on a fine spatial scale for 2 species of seagrass (between rhizosphere and rhizoplane); this finding has consequences for interpreting results from analyses of microbial activity from whole sediment cores from seagrass beds.

\section{Region}

The microbial response was influenced by the distance of the sample from the root surface. Halodule wrigthii rhizoplane samples had consistently higher maximum peaks and faster minimum response times to carbon substrates than samples from the rhizosphere. The difference between rhizosphere and rhizoplane samples suggests that the utilization of the carbon substrate is favoured in the rhizoplane due to increased density or increased cell-specific activity of oxygen-consuming microbes capable of utilizing the substrate provided. It seems probable that greater numbers of aerobic heterotrophs are present in the rhizoplane as oxygen is supplied through the aerenchyma to produce the greatest concentration of oxygen close to the root surface (Connell et al. 1999, Jensen et al. 2005), although higher cell-specific activity in this region cannot be ruled out. Faster substrate utilisation was also observed for Syringodium filiforme rhizoplane (than in the rhizosphere), where patterns of utilisation of sole carbon sources mirrored closely that observed for $H$. wrightii.

The microbial community varied in functional profile within each region, as the responses did not show a proportional increase or decrease across all substrates. The comparison of rhizoplane and rhizosphere response over a $2 \mathrm{wk}$ study period showed a significant interaction between region and substrate $(p<0.0001)$. Additionally, this variation in substrate utilisation amongst regions can be seen in both the 2 species comparison and the shading experiment.

\section{Nutrient limitation}

The activity of the microbial community associated with seagrass roots appeared consistently nutrient-limited within the microtitre wells, suggesting that labile carbon was not limiting in the assay. Relatively faster minimum responses and higher maximum peaks were observed for the substrates containing either nitrogen or phosphorus (e.g. amino acids and natural extracts). The addition of nutrients to the wells prior to incubation significantly reduced minimum response times and increased maximum peaks for all substrates in all samples. Rhizosphere samples showed the greatest reductions in minimum response times following nutrient addition, suggesting relatively more nutrient limitation in the rhizosphere than the rhizoplane.

\section{Species}

The role of seagrass roots in determining microbial activity associated with seagrass sediments has previously been suggested (Pereg et al. 1994, Küsel et al. 2006). The present study compared microbial communities from 2 quite similar species of seagrass: Halodule wrightii and Syringodium filiforme have been reported to have similar minimum light requirements $(17.2 \%$ of surface irradiance in the Indian River Lagoon; Duarte 1991, Dennison et al. 1993), and both species grew to the same maximum depths within the Indian River Lagoon (Kenworthy \& Fonseca 1996).

The results from the present study suggest that differences in oxygen diffusion between species may have contributed to substrate utilization and changes in microbial function. The patterns obtained with CLPP suggested a larger or more active aerobic microbial community was present in Halodule wrightii than Syringodium filiforme rhizosphere samples. One explanation may be that $H$. wrightii releases more oxygen into the rhizosphere than $S$. filiforme, creating a physically larger oxic microzone. Unfortunately, whilst root oxygen loss rates have been characterised for Zostera marina L. and Halophila ovalis (R. Br.) Hook. $f$. (Connell et al. 1999, Jensen et al. 2005), they remain unknown for most species of seagrass, including $H$. wrightii and S. filiforme.

However, a number of other explanations exist for the differences observed in microbial response between the 2 seagrass species. Physical differences in root size may have been a contributing factor. Halodule wrightii appeared to have narrower roots than Syringodium filiforme, although root length was quite similar between species. The smaller cross-section of $H$. wrightii would result in a larger root surface area per unit dry weight of root for microbial colonization. This larger surface area, and potentially greater microbial colonization, could be responsible for the faster response times observed for the $H$. wrightii samples. Alternatively, the extraction efficiency for detaching microorganisms into the inoculum solution may have been different between the 2 species of seagrass, perhaps due to a difference in biofilm texture. 
For the inoculums tested, Halodule wrightii rhizosphere samples utilised natural extracts (from either species) more rapidly than Syringodium filiforme rhizosphere samples. For both species natural extracts gave a faster response time than sole substrates, and this was thought to be either due to the alleviation of nutrient limitation or a more labile source of carbon within the natural extract. Faster utilisation of natural extracts by rhizosphere samples of $H$. wrightii (compared to $S$. filiforme) was probably due to the presence of more active oxygen-consuming bacteria. Faster utilization away from the root surface could be due to a larger oxic microzone surrounding the roots of $H$. wrightii than $S$. filiforme. The difference between utilisation rates of the rhizosphere samples was not observed when inoculated with sole substrates, and suggests that nutrient limitation of these samples may have masked any difference in substrate utilisation capacity.

\section{Shading}

Shading of seagrass may have had several effects within the associated microbial community. Shading may reduce the oxic zone surrounding roots, as most root oxygen loss is dependent on photosynthesis (Connell et al. 1999, Colmer 2003); however, oxygen can also diffuse passively from the roots during dark periods (Pedersen et al. 1998, Borum et al. 2006). If the oxygenated zone surrounding the seagrass roots was reduced following shading, this could affect the number or activity of oxygen-consuming microbes in the rhizosphere without necessarily affecting the rhizoplane microbial activity. With a less active aerobic microbial community, competition for nutrients would be reduced, potentially resulting in a faster minimum response time (as was observed). Shading may have also altered the organic carbon provided by the plant roots to the sediment. If the microbial community was starved for a labile source of carbon, it is possible that the microbial community entered a starvation mode. In a starvation mode, greater endogenous respiration would be observed as more oxygen consumption but does not necessarily indicate greater substrate assimilation. From the data gathered it is not possible to determine if the faster minimum response time was due to a starvation response or alleviation of nutrient stress.

We also observed that nutrient addition reduced minimum response times and increased maximum peaks, and dominated responses observed for shading. For non-nutrient supplemented samples, the minimum response time for substrate utilisation was reduced in shaded treatments compared to unshaded treatments.

\section{Responses to substrates}

All carbon substrates tested were utilised to some degree. Nutrient limitation appeared to be the strongest determinant of maximum peaks obtainable. Under non-nutrient supplemented conditions, rhizome extract and asparagine produced the highest responses (probably as these substrates contained nitrogen). With the addition of nutrients to the samples (in the shading experiment), there was a $\sim 3$ - to 5-fold increase in the maximum peaks observed for mannose, asparagine, acetate and propionic acid. The stock solutions of these 4 substrates were standardised to provide $100 \mathrm{ppm}$ of carbon to the wells and provided similar maximum peaks with added nutrients. The relatively small increase in response peak for rhizome extract following nutrient addition may be the result of less carbon available initially when compared to the sole substrates, although carbon concentration in the rhizome extract was not determined.

\section{Limitations of the present study}

Standardisation of the inoculum on a per root basis (by standardising the mass of root used in the preparation of the inoculum) rather than determining the actual inoculum cell density results in some limitations on the interpretation of results. Whilst inoculum density will affect the rate of response in the BD-oxy assay, we do not believe that variation in inoculum density confounds our conclusion regarding the relative activity of the rhizoplane and rhizopshere for a given amount of root. However, we cannot distinguish whether differences in responses observed are due to the presence of more cells possessing that functional trait or a greater activity per cell.

Differences observed in the present study may be due to population-size or physiological differences in the microbial community. Without combining the BDoxy CLPP assay with molecular techniques similar to those used by Jensen et al. (2007) for Zostera marina, this question cannot be addressed. Conversely, molecular techniques alone tell us little about the activity of the microbial community.

The potential contribution to respiration by benthic microalgae or marine fungi was not determined in the present study. Incubations occurred primarily in the dark, although excitation of the fluorescent dye did occur in each well every $15 \mathrm{~min}$. The fluorescent dye response to oxygen consumption is most probably the sum of respiration and utilisation of organic matter by aerobic heterotrophs with contributions also from respiration of benthic microalgae and/or marine fungi. 
It is well known that microbial biomass and activity within seagrass beds varies seasonally (Danovaro et al. 1994, Glazebrook et al. 1996, Holmer \& Kristensen 1996, Welsh et al. 1996). Additionally, diurnal patterns in photosynthesis are likely to affect both oxygen dynamics and microbial activity (Lee \& Dunton 2000). Patterns in substrate utilisation are also likely to be linked to seasonal and diurnal patterns, but these were not considered in the present study.

\section{Potential management applications}

The link between aerobic microbial activity and plant productivity could be further explored to enhance the understanding of seagrass health for management purposes. Seagrasses appear to become stressed following an imbalance of carbon and oxygen in the rhizosphere, which results in a reduced ability to maintain oxygenated root zone (Lee \& Dunton 2000, Holmer \& Bondgaard 2001). Negative impacts on seagrass are more commonly observed only after the impact of multiple stressors (Koch \& Erskine 2001, Koch et al. 2007). If a link between bacterial activity and seagrass productivity can be established it might allow for improved monitoring of seagrass health; however, more research is needed before the BD-oxy community-level physiological profiling assay could be applied routinely.

Acknowledgements. This work was supported by the Marine Biological Laboratory's NASA Planetary Biology Internship program. We thank staff from the Dynamac Corporation at the Kennedy Space Center for their assistance with field and laboratory components of this work. The authors appreciate the improvements to the manuscript suggested by the editor and 3 anonymous reviewers.

\section{LITERATURE CITED}

Blaabjerg V, Finster K (1998) Sulphate reduction associated with roots and rhizomes of the marine macrophyte Zostera marina. Aquat Microb Ecol 15:311-314

Blaabjerg V, Mouritsen KN, Finster K (1998) Diel cycles of sulphate reduction rates in sediments of a Zostera marina bed (Denmark). Aquat Microb Ecol 15:97-102

Boon PI, Moriarty DJW, Saffigna PG (1986) Rates of ammonium turnover and the role of amino-acid deamination in seagrass (Zostera capricorni) beds of Moreton Bay, Australia. Mar Biol 91:259-268

Borum J, Sand-Jensen K, Binzer T, Pedersen O, Greve T (2006) Oxygen movement in seagrasses. In: Larkum AWD, Orth RJ, Duarte CM (eds) Seagrasses: biology, ecology and conservation. Springer, Dordrecht, p 255-270

> Boschker HTS, Wielemaker A, Schaub BEM, Holmer M (2000) Limited coupling of macrophyte production and bacterial carbon cycling in the sediments of Zostera spp. meadows. Mar Ecol Prog Ser 203:181-189

Cifuentes A, Antón J, Benlloch S, Donnelly A, Herbert RA, Rodríguez-Valera F (2000) Prokaryotic diversity in Zostera noltii-colonized marine sediments. Appl Environ Microbiol 66:1715-1719

Cifuentes A, Antón J, de Wit R, Rodríguez-Valera F (2003) Diversity of Bacteria and Archaea in sulphate-reducing enrichment cultures inoculated from serial dilution of Zostera noltii rhizosphere samples. Environ Microbiol 5:754-764

Colmer TD (2003) Long-distance transport of gases in plants: a perspective on internal aeration and radial oxygen loss from roots. Plant Cell Environ 26:17-36

> Connell EL, Colmer TD, Walker DI (1999) Radial oxygen loss from intact roots of Halophila ovalis as a function of distance behind the root tip and shoot illumination. Aquat Bot 63:219-228

> Danovaro R, Fabiano M, Boyer M (1994) Seasonal changes in benthic bacteria in a seagrass bed (Posidonia oceanica) of the Ligurian Sea in relation to origin, composition and fate of the sediment organic matter. Mar Biol 119:489-500

Dennison WC, Orth RJ, Moore KA, Stevenson JC and others (1993) Assessing water quality with submerged aquatic vegetation. Bioscience 43:86-94

Donnelly AP, Herbert RA (1999) Bacterial interactions in the rhizosphere of seagrass communities in shallow coastal lagoons. J Appl Microbiol (Suppl) 85:151S-160S

> Duarte CM (1991) Seagrass depth limits. Aquat Bot 40: 363-377

> Garland JL, Roberts MS, Levine LH, Mills AL (2003) Community-level physiological profiling performed with an oxygen-sensitive fluorophore in a microtitre plate. Appl Environ Microbiol 69:2994-2998

Glazebrook PW, Moriarty DJW, Hayward AC, MacRae IC (1996) Seasonal changes in numbers and the location of a particular bacterial strain of Alteromonas sp. in seagrass sediments. Microb Ecol 31:1-13

> Hansen JW, Udy JW, Perry CJ, Dennison WC, Lomstein BA (2000) Effect of the seagrass Zostera capricorni on sediment microbial processes. Mar Ecol Prog Ser 199:83-96

Holmer M, Bondgaard EJ (2001) Photosynthetic and growth response of eelgrass to low oxygen and high sulfide concentrations during hypoxic events. Aquat Bot 70:29-38

> Holmer M, Kristensen E (1996) Seasonality of sulfate reduction and pore water solutes in a marine fish farm sediment: the importance of temperature and sedimentary organic matter. Biogeochemistry 32:15-39

> Holmer M, Andersen FØ, Nielsen SL, Boschker HTS (2001) The importance of mineralization based on sulfate reduction for nutrient regeneration in tropical seagrass sediments. Aquat Bot 71:1-17

Holmer M, Duarte CM, Boschker HTS, Barrón C (2004) Carbon cycling and bacterial carbon sources in pristine and impacted Mediterranean seagrass sediments. Aquat Microb Ecol 36:227-237

Jensen SI, Kühl M, Glud RN, Jørgensen LB, Priemé A (2005) Oxic microzones and radial oxygen loss from roots of Zostera marina. Mar Ecol Prog Ser 293:49-58

Jensen SI, Kühl M, Priemé A (2007) Different bacterial communities associated with the roots and bulk sediment of the seagrass Zostera marina. FEMS Microbiol Ecol 62: $108-117$

Jones WB, Cifuentes LA, Kaldy JE (2003) Stable carbon isotope evidence for coupling between sedimentary bacteria and seagrass in a sub-tropical lagoon. Mar Ecol Prog Ser 255:15-25

> Kaldy JE, Eldridge PM, Cifuentes LA, Jones WB (2006) Utilization of DOC from seagrass rhizomes by sediment bacteria: ${ }^{13} \mathrm{C}$ tracer experiments and modeling. Mar Ecol Prog Ser 317:41-55 
Kenworthy WJ, Fonseca MS (1996) Light requirements of seagrasses Halodule wrightii and Syringodium filiforme derived from the relationship between diffuse light attenuation and maximum depth distribution. Estuaries 19: 740-750

Koch MS, Erskine JM (2001) Sulfide as a phytotoxin to the tropical seagrass Thalassia testudinum: interactions with light, salinity and temperature. J Exp Mar Biol Ecol 266: 81-95

Koch MS, Schopmeyer SA, Kyhn-Hansen C, Madden CJ (2007) Synergistic effects of high temperature and sulfide on tropical seagrass. J Exp Mar Biol Ecol 341:91-101

Konopka A, Oliver L, Turco RF Jr (1998) The use of carbon substrate utilization patterns in environmental and ecological monitoring. Microb Ecol 35:103-115

Kurtz JC, Yates DF, Macauley JM, Quarles RL, Genthner FJ, Chancy CA, Devereux R (2003) Effects of light reduction on growth of the submerged macrophyte Vallisneria americana and the community of root-associated heterotrophic bacteria. J Exp Mar Biol Ecol 291:199-218

Küsel K, Trinkwalter T, Drake HL, Devereux R (2006) Comparative evaluation of anaerobic bacterial communities associated with roots of submerged macrophytes growing in marine or brackish water sediments. J Exp Mar Biol Ecol 337:49-58

Lee KS, Dunton KH (2000) Diurnal changes in pore water sulfide concentrations in the seagrass Thalassia testudinum beds: the effects of seagrasses on sulfide dynamics. J Exp Mar Biol Ecol 255:201-214

Moriarty DJW, Pollard PC (1982) Diel variation of bacterial productivity in seagrass (Zostera capricorni) beds measured by rate of thymidine incorporation into DNA. Mar Biol 72:165-173

Nielsen LB, Finster K, Welsh DT, Donnelly A, Herbert RA, de Wit R, Lomstein BA (2001) Sulphate reduction and nitro-

Editorial responsibility: Rutger de Wit, Montpellier, France gen fixation rates associated with roots, rhizomes and sediments from Zostera noltii and Spartina maritima meadows. Environ Microbiol 3:63-71

> Pedersen O, Borum J, Duarte CM, Fortes MD (1998) Oxygen dynamics in the rhizosphere of Cymodocea rotundata. Mar Ecol Prog Ser 169:283-288

> Pereg LL, Lipkin Y, Sar N (1994) Different niches of the Halophila stipulacea seagrass bed harbor distinct populations of nitrogen fixing bacteria. Mar Biol 119: $327-333$

Pollard PC, Kogure K (1993) Bacterial decomposition of detritus in a tropical seagrass (Syringodium isoetifolium) ecosystem measured with [methyl- ${ }^{3} \mathrm{H}$ ] thymidine. Aust $\mathrm{J}$ Mar Freshw Res 44:155-172

Smith AC, Kostka JE, Devereux R, Yates DF (2004) Seasonal composition and activity of sulfate-reducing prokaryotic communities in seagrass bed sediments. Aquat Microb Ecol 37:183-195

Väisänen RK, Roberts MS, Garland JL, Frey SD, Dawson LA (2005) Physiological and molecular characterisation of microbial communities associated with different waterstable aggregate size classes. Soil Biol Biochem 37: $2007-2016$

Welsh DT, Bourguès S, de Wit R, Herbert RA (1996) Seasonal variations in nitrogen-fixation (acetylene reduction) and sulphate-reduction rates in the rhizosphere of Zostera noltii: nitrogen fixation by sulphate-reducing bacteria. Mar Biol 125:619-628

- Welsh DT, Bourguès S, de Wit R, Auby I (1997) Effect of plant photosynthesis, carbon sources and ammonium availability on nitrogen fixation rates in the rhizosphere of Zostera noltii. Aquat Microb Ecol 12:285-290

Ziegler S, Benner R (1999) Dissolved organic carbon cycling in a subtropical seagrass-dominated lagoon. Mar Ecol Prog Ser 180:149-160

Submitted: September 8, 2008; Accepted: June 8, 2009 Proofs received from author(s): August 12, 2009 